\title{
Factors Associated with Cognitive Decline in Transient Ischemic Attack Patients
}

\author{
Leka Sivakumar, Richard Camicioli, Ken Butcher
}

\begin{abstract}
Chronic cerebrovascular disease and large ischemic stroke are both associated with cognitive impairment. Much less is known about the acute cognitive sequelae of transient ischemic attack (TIA). Although often overlooked, there is increasing evidence that cognitive impairment does occur following TIA. In some patients, cognitive changes persist after resolution of focal neurological deficits, but the temporal profile of these symptoms is unknown. In addition, clinical and imaging correlates of cognitive impairment after TIA have not been systematically studied. This under-studied and recognized problem has significant implications for TIA patient management. In this review, we summarize the evidence currently available and identify future research priorities.
\end{abstract}

RÉSUMÉ: Facteurs associés au déclin cognitif chez les patients présentant un accident ischémique transitoire. La maladie vasculaire cérébrale chronique et l'accident vasculaire cérébral extensif sont tous deux associés à un déficit cognitif. On connaît moins bien les séquelles cognitives aiguës d'un accident ischémique transitoire (AIT). Bien que ce soit rarement pris en compte, il y a de plus en plus de données en faveur de la présence d'un déficit cognitif suite à un AIT. Chez certains patients, les changements cognitifs persistent après la résolution des déficits neurologiques focaux, mais le profil temporel de ces symptômes demeure inconnu. De plus, les corrélats cliniques et d'imagerie du déficit cognitif après un AIT n'ont pas été étudiés systématiquement. Ce problème peu étudié comporte des implications importantes pour le traitement des patients ayant présenté un AIT. Dans cette revue, nous faisons un sommaire des données disponibles et nous identifions les priorités à considérer dans des études futures.

Can J Neurol Sci. 2014; 41: 303-313

Stroke is the leading cause of prolonged disability in the elderly and the second most common cause of death. ${ }^{1,2}$ Prior to stroke individuals often experience minor cerebrovascular events such as transient ischemic attacks (TIAs). According to the World Health Organization criteria, a TIA is defined as a focal neurological deficit lasting for less than 24 hours and presumed to be of vascular origin. ${ }^{3}$ These events have been considered crucial "warning signs" for increased risk of an upcoming stroke. Stroke has been shown to follow a TIA in 12 to $30 \%$ of patients, and the highest risk of recurrent cerebral ischemia is within the first 24 hours of the initial event. ${ }^{4}$ Without early detection and proper treatment, TIAs can be followed by more severe ischemic stroke.

Cerebrovascular disease is associated with cognitive impairment that significantly impacts patients in the long term. Up to $25 \%$ of stroke survivors meet the criteria for dementia within 12 months of an ischemic event., ${ }^{5,6}$ Chronic cerebrovascular changes, without overt clinical evidence of an ischemic stroke, can lead to cognitive decline, ultimately resulting in vascular dementia. In TIA patients, symptoms and tissue deficits are by definition considered temporary, but cognitive impairments have been identified in some studies after initial focal symptoms have resolved. ${ }^{7-9}$ Imaging studies in TIA/minor stroke patients have identified correlates of cognitive deficits, but a profile describing how cognitive changes evolve over time has not been established. It is unknown whether cognitive impairments remain stable, worsen, or resolve in time and what factors may significantly predict these changes. These factors are relevant to managing patient rehabilitation and making informed decisions related to return to previous activities including work and driving.

The purpose of this review is to provide an overview of imaging and clinical factors correlated with impairments in cognition function, describe existing temporal profiles of cognitive change and address current therapeutic strategies for treating cognitive decline in TIA patients.

\section{Imaging Studies in TIA Patients \\ Imaging Modalities Used in TIA}

It has been estimated that approximately one third of patients diagnosed with a TIA on clinical grounds alone, actually have evidence of an infarct on magnetic resonance imaging (MRI) scan. ${ }^{10,11}$ This has resulted in a paradigm shift in the approach to TIA/minor stroke, which are now viewed as a spectrum of the acute cerebrovascular presentation, rather than discrete

\footnotetext{
From the Division of Neurology, University of Alberta, Edmonton, Alberta, Canada Received April 30, 2013. Final Revisions Submitted DeCEmber 12, 2013 Correspondence to: Ken Butcher, 2E3 WMC Health Sciences Centre, University of Alberta, 8440 112th St., Edmonton, Alberta, T6G 2B7, Canada.

Email: ken.butcher@ualberta.ca.
} 
Table 1: Computed tomography studies in transient ischemic attack patients

\begin{tabular}{|c|c|c|c|c|}
\hline Study (Reference) & $\begin{array}{l}\text { Time from Symptom } \\
\text { Onset to Scan }\end{array}$ & TIA Inclusions & $\begin{array}{c}\text { \# of } \\
\text { Patients }\end{array}$ & $\begin{array}{l}\% \text { of TIA Patients } \\
\text { With Infarct }\end{array}$ \\
\hline Perrone et al..$^{14} 1979$ & & All TIAs & 35 & 34 \\
\hline Calandre et al. ${ }^{15} 1984$ & Mean 50 days & All TIAs & 88 & 25 \\
\hline Awad et al. ${ }^{16} 1986$ & & All TIAs & 22 & 32 \\
\hline Davalos et al. ${ }^{17} 1988$ & & & 122 & 21 \\
\hline Murros et al. ${ }^{18} 1989$ & Within 4 weeks & Carotid TIA & 284 & 12 \\
\hline Dennis et al. ${ }^{19} 1990$ & $\begin{array}{l}\text { Median } 11 \text { days } \\
\text { (IQR 5-23 days) }\end{array}$ & All TIAs & 120 & 27 \\
\hline Evans et al..$^{20} 1991$ & Within 4 weeks & All TIAs & 350 & 17 \\
\hline Eliasziw et al. ${ }^{21} 1995$ & & All TIAs & 164 & 28 \\
\hline Douglas et al..$^{22} 2003$ & Within $48 \mathrm{~h}$ & All TIAs & 478 & 4 \\
\hline Al-Khaled et al..$^{23} 2012$ & Within $48 \mathrm{~h}$ & All TIAs & 1533 & 3 \\
\hline
\end{tabular}

CT indicates computed tomography; TIA, transient ischemic attack.

entities. ${ }^{12}$ The fact that patients with transient symptoms often have evidence of parenchymal brain injury indicates that the condition is not as benign as once believed. Transient ischemic attack-related infarcts can be difficult to detect because they are often very small - generally less than $1 \mathrm{~mL}$ in volume. ${ }^{13}$

Although evidence of infarction can be seen on computed tomography (CT) after TIA, these are often chronic infarcts and unrelated to the acute presentation. Nonetheless, these lesions are of prognostic value. In 1979, Perrone et al found that $34 \%$ of TIA patients had small hypodense areas on CT. ${ }^{14}$ Subsequent studies have reported lower percentages ranging from $3 \%$ to $32 \%^{15-23}$ (Table 1). Interestingly a study in 1983, examining the case reports of two patients with TIA symptoms, demonstrated evolving infarcts on cranial $\mathrm{CT}^{24}$ These authors suggested that patients, who fit the temporal profile of TIA, but showed evidence of infarction on CT, should be classified separately as cerebral infarction with transient signs. In the most recent CT study, a cohort of 1533 TIA patients were scanned within 48 hours of symptom onset. ${ }^{23}$ Evidence of a suspected new infarct was detected in $3.1 \%$ of patients, but this is much lower than that seen with MRI. ${ }^{11}$
More recent MRI studies have changed the approach to diagnosis of the TIA/minor stroke patient. The MRI diffusionweighted imaging (DWI) sequence in particular has a high sensitivity for detecting acute cerebral ischemia. The DWI sequence is particularly sensitive to the movement of protons, and therefore water molecules in the brain. Areas of increased intensity on DWI represent diffusion restriction. The latter is associated with bio-energetic compromise and cytotoxic edema formation during an ischemic event. ${ }^{25}$ Studies of TIA patients utilizing DWI have demonstrated higher infarct detection rates in comparison to CT. A prospective study of 22 TIA patients found focal CT changes in 7 (32\%) patients, however using DWI, focal abnormalities were detected in as many as 17 (77\%). ${ }^{16}$ More recently, a study of 161 TIA patients, who underwent both $\mathrm{CT}$ and MRI, indicated focal CT abnormalities in seven $(4.3 \%)$ patients. ${ }^{26}$ The overall agreement between CT and MRI in detecting ischemic lesions was $69 \%$, indicating that approximately one third of identified DWI lesions were missed or misidentified (i.e. chronic lesions classified as acute relevant infarct) on CT.

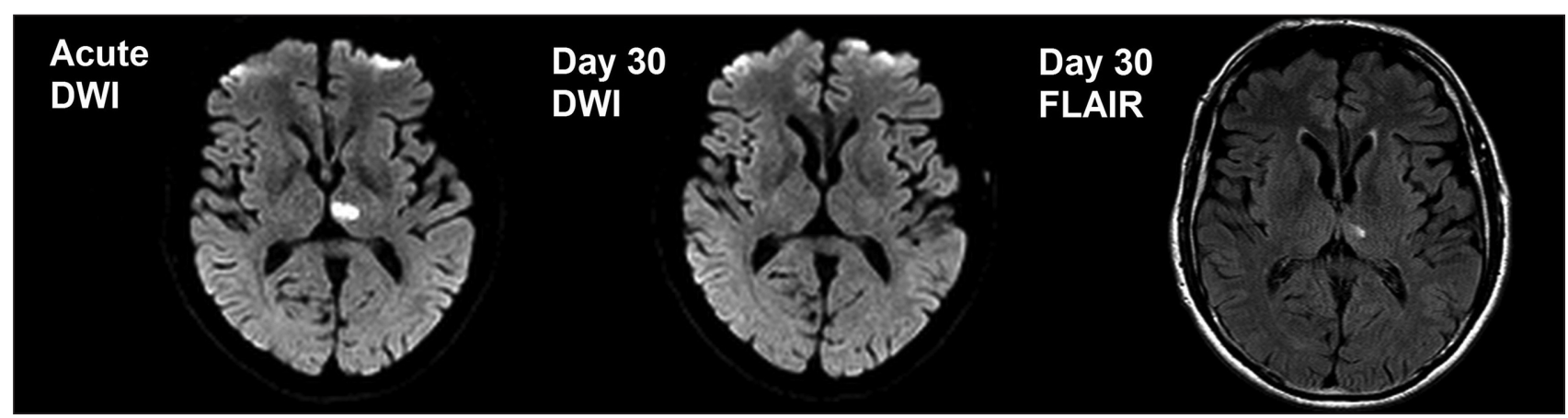

Figure: MRI findings including DWI and FLAIR sequences in a TIA patient scanned acutely and at day 30. Acute DWI demonstrates a small ischemic lesion, which is seen to resolve by day 30. Bright signal intensity seen on the day 30 FLAIR image indicates a chronic infarct. MRI indicates magnetic resonance imaging; DWI, diffusion-weighted imaging; FLAIR, fluid attenuated inversion recovery; TIA, transient ischemic attack. 
Table 2: MRI (DWI) studies in transient ischemic attack patients

\begin{tabular}{|c|c|c|c|c|}
\hline Study (Reference) & $\begin{array}{l}\text { Time from Symptom } \\
\text { Onset to Scan }\end{array}$ & TIA Inclusions & \# of Patients & $\begin{array}{l}\% \text { of TIA Patients } \\
\text { With Infarct }\end{array}$ \\
\hline Kidwell et al. ${ }^{27} 1999$ & Mean $17 \mathrm{~h}$ & Cerebral and brainstem & 42 & 48 \\
\hline Engelter et al. ${ }^{28} 1999$ & Mean $36.5 \mathrm{~h}$ & Any focal deficit $<24 \mathrm{~h}$ & 40 & 35 \\
\hline Takayama et al. ${ }^{29} 2000$ & Within $48 \mathrm{~h}$ & All TIAs & 19 & 37 \\
\hline Kamal et al. ${ }^{30} 2002$ & Within 6h & All TIAs & 28 & 46 \\
\hline Ay et al..$^{13} 2002$ & Mean 39h & Cerebral and brainstem & 57 & 47 \\
\hline Marx et al..$^{31} 2002$ & Mean $10.7 \mathrm{~h}$ & Brainstem & 14 & 29 \\
\hline Kastrup et al..$^{32} 2002$ & $\begin{array}{l}\text { Mean } 5 \text { days }(\mathrm{DWI}+) \\
\text { Mean } 6 \text { days (DWI -) }\end{array}$ & Carotid TIA & 42 & 45 \\
\hline Rovira et al. ${ }^{33} 2002$ & Mean 5 days & Cerebral and brainstem & 58 & 67 \\
\hline Crisostomo et al. ${ }^{34} 2003$ & Mean 23h & All TIAs & 75 & 21 \\
\hline Nagura et al.$^{35} 2003$ & Median $17.3 \mathrm{~h}$ & All TIAs & 45 & 31 \\
\hline Nakamura et al. ${ }^{36} 2003$ & Within $48 \mathrm{~h}$ & All TIAS & 18 & 50 \\
\hline Restrepo et al. ${ }^{37} 2004$ & $\begin{array}{l}\text { Mean } 56 \min (\mathrm{DWI}+) \\
\text { Mean } 33 \min (\mathrm{DWI}-)\end{array}$ & All TIAs & 22 & 55 \\
\hline Purroy et al..$^{38} 2004$ & Within 7 days & Cerebral and brainstem & 83 & 33 \\
\hline Winbeck et al. ${ }^{39} 2004$ & Within $24 \mathrm{~h}$ & Anterior circulation & 60 & 30 \\
\hline Schulz et al. ${ }^{40} 2004$ & Median 17 days & All TIAs & 136 & 13 \\
\hline Inatomi et al..$^{41} 2004$ & Median 4 days & Cerebral and brainstem & 129 & 44 \\
\hline Ay et al. ${ }^{42} 2005$ & Mean/SD $22 \pm 26 h$ & Cerebral and brainstem & 87 & 41 \\
\hline Coutts et al..$^{43} 2005$ & Median $8.5 \mathrm{~h}$ & TIA and MS $(\mathrm{NIH}<6)$ & 143 & 68 \\
\hline Oppenheim et al. ${ }^{44} 2006$ & Median 24h & All TIAs & 103 & 35 \\
\hline Lamy et al.$^{45} 2006$ & Mean $42.4 \mathrm{~h}$ & Cerebral and brainstem & 98 & 35 \\
\hline Prabhakaran et al. ${ }^{46} 2007$ & Within $48 \mathrm{~h}$ & All TIAs & 146 & 25 \\
\hline Redgrave et al..$^{47} 2007$ & Within $72 \mathrm{~h}$ & All TIAs & 200 & 16 \\
\hline Calvet et al..$^{48} 2009$ & Median 19.5h & All TIAs & 339 & 40 \\
\hline Mlynash et al. ${ }^{49} 2009$ & Mean/SD $23.2 \pm 12.5 \mathrm{~h}$ & All TIAs & 43 & 35 \\
\hline Adeoye et al. ${ }^{50} 2010$ & Within $48 \mathrm{~h}$ & All TIAs & 323 & 15 \\
\hline Al-Khaled et al. ${ }^{51} 2013$ & Within 48h & Time defined TIAs & 1862 & 11 \\
\hline Miyagi et al..$^{52} 2013$ & Within 7 days & All TIAs & 458 & 21 \\
\hline
\end{tabular}

MRI indicated magnetic resonance imaging; DWI, diffusion-weighted imaging; TIA, transient ischemic attack.

Systematic MRI studies have found that the proportion of TIA patients with positive DWI changes ranges from $11 \%$ to $68 \%^{13,27-52}$ (Table 2). The discrepancy in this large range of reported values may be explained by variations in study design, study population and sample size. For example, time from symptom onset to MRI scan varied from within six hours to a median 17 days later. In studies reporting later time points, DWI infarcts may have resolved, while acute studies may have more frequently reported positive DWI scans. Additionally, although all studies included TIA patients, some also included minor stroke and population sizes ranged from 14 to 1862 patients. Serial imaging studies indicate that some DWI lesions do result in a visible chronic infarct (Figure), while others do not. In a study of 42 TIA patients, relevant DWI abnormalities were reported in nearly half of patients. ${ }^{27}$ Of the nine DWI positive patients who had a follow-up imaging study two to seven months after the event, four did not reveal any infarct relevant to the original abnormality. In another multicenter study, DWI scans were performed within 24 hours of symptom onset in 458 patients and acute ischemic lesions were found in $96(21 \%)$ patients. ${ }^{52}$ A follow-up MRI was done on 48 patients showing that in five (10.4\%), DWI lesions visible on admission had disappeared. In a study by Oppenheim and colleagues, $21 \%$ of TIA patients with baseline positive DWI scans showed no permanent injury when assessed 11.6 months later. ${ }^{44}$ Lesions that 'reversed' had smaller initial DWI volumes than those that infarcted. Although this phenomenon has been referred to as 'DWI reversal' it more likely represents a very small infarct that is below the resolution of standard MRI.

\section{Imaging Correlates of Cognitive Impairment}

Studies identifying clinical characteristics associated with the presence of DWI abnormalities in TIA patients focus more strongly on functional impairments than cognitive deficits. A longer duration of neurological symptoms and the presence of motor weakness are both associated with the presence of DWI lesions. ${ }^{34,41}$ The impact of DWI lesion presence, location, volume and number on cognitive performance is unknown. Studies correlating MRI findings in TIA patients with neuropsychological testing are lacking. There is an increased likelihood of aphasia in TIA patients with DWI lesion, but the relationship to other cognitive domains is unknown. ${ }^{45,51}$ One study found that TIA patients with a positive DWI scan were 25 times more likely to have aphasia than those with negative 
scans. ${ }^{34}$ In a study of 147 TIA patients, disturbance of higher cortical function evidence such as aphasia and spatial neglect was a significant factor associated with DWI abnormalities. ${ }^{41}$

Although DWI lesion characteristics in TIA patients such as volume, location and frequency have been reported, studies investigating the association of these parameters with cognitive impairments are very scarce. In the Sydney Stroke Study, 170 patients with stroke or TIA and 96 age-matched controls were examined between three to six months following the event. ${ }^{53}$ Patients were categorized as having vascular dementia, vascular cognitive impairment (VCI) or no cognitive impairment by consensus and administered detailed neuropsychological testing along with an MRI scan. Although vascular dementia subjects had larger infarct volumes than VCI subjects, cognitive impairments were not significantly correlated with volume or number of infarctions. Instead, a significant relationship was observed between chronic deep white matter hyperintensities and cognitive deficits.

\section{Cognitive Performance Testing After Stroke and TIA}

\section{Cognitive Screening Assessments in Acute Ischemic Stroke}

Cognitive function is often compromised after stroke, but is rarely assessed in stroke trials. Cognitive changes in acute stroke patients have been assessed quantitatively using different batteries of neuropsychological tests. While detailed neuropsychological testing represents the gold standard in terms of identifying cognitive impairment, this is generally impractical in the acute setting, partially motivating the need for brief yet accurate instruments. The two most commonly utilized tests in cognitive screening for acute stroke are the Mini-Mental State Examination (MMSE) and the Montreal Cognitive Assessment (MoCA).

The MMSE, developed by Folstein et al, is a cognitive assessment of patient mental state and has been considered the clinical standard in stroke. ${ }^{54}$ The assessment comprises a battery of individual tests that can be administered in approximately ten minutes. The test is scored out of a total of 30 points, with higher scores indicating higher functioning. Items are grouped into categories to test orientation, registration, recall, calculation and attention, naming, repetition, comprehension, reading, writing and drawing. The MMSE has however been criticized for being insensitive to mild cognitive impairment (MCI). This test also primarily focuses on assessing memory and language abilities while it fails to assess executive function, a common impairment in cerebrovascular disease.

The MoCA was a test designed more recently as a cognitive screening assessment with increased sensitivity to MCI. ${ }^{55}$ The MoCA can be administered in a short ten minutes, where patients can score a total of 30 points. The test is divided into eight sections assessing the cognitive domains of visuo-executive function, naming, memory, attention, language, abstraction, delayed recall and orientation. Cognitive impairment based on MoCA scoring has been designated by a cutoff score less than $26.55,56$

A number of factors make accurate assessment of cognitive impairment following stroke/TIA challenging. Depression present following acute stroke has been implicated in worse functional outcome and also exacerbates any acute/chronic cognitive impairment. ${ }^{57-59}$ Cognitive assessments also vary in their sensitivity for mild impairment. A validation study by Nassreddine and colleagues in 2005 compared the sensitivities of MMSE and MoCA in 94 patients who met the criteria for MCI. ${ }^{55}$ The MMSE had a sensitivity of $18 \%$ in MCI patients, whereas the MoCA had a sensitivity of $90 \%$. Several studies comparing MoCA and MMSE in acute stroke and TIA patients have shown that MoCA is superior to the MMSE in detecting MCI. ${ }^{56,60-62}$ Despite this, many studies continue to utilize MMSE.

There is no consensus on the cognitive test most appropriate for assessment of post stroke cognitive impairment. A number of studies have compared MoCA and MMSE after TIA with other methods of evaluation including the Addenbrooke's Cognitive Examination Revised (ACE-R), telephone MoCA (T-MoCA) assessment and specific batteries of neuropsychological tests. ${ }^{63-65}$ In a population-based study of 100 patients assessed $\geq$ one year after TIA or stroke, MoCA and MMSE were compared to the ACE-R for detecting MCI, defined using the Neurological Disorders and Stroke-Canadian Stroke Network Vascular Cognitive Impairment Battery. ${ }^{63}$ Both the MoCA and ACE-R had better sensitivity and specificity for MCI compared to the MMSE, which demonstrated a ceiling effect. A study by the same group assessed the T-MoCA against face-to-face cognitive tests in 91 patients with TIA or stroke. ${ }^{64}$ After one year, MoCA subtest scores for repetition, abstraction and verbal fluency were significantly worse by telephone than face-to-face testing. The TMoCA was therefore considered limited in its ability to assess visuoexecutive and complex language tasks. Another study aimed to compare the MoCA with a computerized battery of neuropsychological tests for memory, attention and executive functions to detect mild to moderate cognitive impairments in patients with TIA or stroke. ${ }^{65}$ In comparison to stroke, TIA patients presented significantly better scores through both methods. However, the MoCA was able to identity many more subjects with low scores $(<26)$ compared to the neuropsychological battery.

\section{Cognitive Assessments in Vascular Dementia}

The most widely used criteria for diagnosis of vascular dementia is the National Institute of Neurological Disorders and Stroke and Association Internationale pour la Recherché et l'Ensignement en Neurosciences (NINDS-AIREN) criteria. ${ }^{66}$ These criteria rely on neuroimaging by CT or MRI for evidence of focal brain damage as well as cognitive deficits in at least three cognitive domains (one of which must be memory). Patients are diagnosed as having probably, possible or definite vascular dementia based on the strength of the association between cerebrovascular disease and cognitive impairment. The Alzheimer's disease Assessment Scale (ADAS) is used to assess cognitive dysfunction in individuals with Alzheimer disease and other dementias. ${ }^{67}$ Its subscale, the Alzheimer's disease Assessment Scale-cognitive subscale (ADAS-cog), is the most popular cognitive testing instrument used in clinical trials of nootropics ${ }^{68}$ It consists of 11 tasks measuring the disturbances of memory, language, praxis, attention and other cognitive abilities. 


\section{Cognitive Impairment after TIA}

Cognitive studies in TIA patients have demonstrated that cognitive impairments in many cases do persist beyond the transient event. A comparative study of MoCA and MMSE, in 20 patients diagnosed with TIA or stroke, utilized the MMSE on admission and the MoCA two weeks later. ${ }^{69}$ With cutoffs for impairment set at $\leq 26$, MMSE detected cognitive impairment in $10 \%$ of patients, while MoCA detected impairment in 55\%. In a larger population based study of 413 TIA and stroke patients, the MMSE and MoCA were administered at a six month or five year follow-up. ${ }^{56}$ Defining cognitive impairment as a score of $<27$ on either test, $58 \%$ of patients with an MMSE score within normal limits had an abnormal MoCA. The MoCA indicated poor cognitive function in $70 \%$ of all patients. In a more recent study, cognitive impairment in 97 first time TIA patients was assessed using MoCA and compared to 100 healthy control patients. ${ }^{70}$ TIA patients exhibited declined cognitive function with impairments in verbal fluency, memory recall, abstraction, and visuospatial/executive abilities.

\section{Temporal Pattern of Cognitive Changes after TIA and Minor Stroke}

The temporal pattern of motor, speech and sensory deficits in $\mathrm{TIA} /$ minor stroke is an acute onset and relatively rapid resolution with no long-term sequelae. It is unknown to what extent, if any cognition is affected in this population hyperacutely and whether these deficits actually resolve with the other neurological symptoms. Longitudinal studies that adequately assess this pattern in TIA and minor stroke patients are scarce. Most studies in TIA and minor stroke patients lack serial assessment of cognition at multiple time points, including immediately after symptom onset, and only assess deficits several days after symptom onset. In a cross-sectional study of 280 TIA and minor stroke patients (National Institutes of Health Stroke Scale $\leq 3$ ), MMSE was administered both at the initial assessment (baseline) and one month later and then repeated at one, two and five years. ${ }^{7}$ Patients were divided into two baseline groups: those seen between one and seven days and those seen between 8 and 20 days. Transient cognitive impairment (TCI) was defined as a baseline MMSE score $\geq 2$ points lower than the one month follow-up MMSE. The rate of TCI in patients initially assessed within seven days (median four days) was $38.9 \%$. This was higher than the rate of $19 \%$ seen in those examined between 8 and 20 days (median 12 days). Patients with TCI did show a recovery in mean MMSE scores from $23.9 \pm 3.6$ at baseline to $27.2 \pm 3.0$ at one month. Sachdev and colleagues examined 128 stroke or TIA patients aged 49 to 87 years, with no history of dementia or aphasia as a limiting factor $(<3$ on the Aphasia Severity Rating Scale). ${ }^{8}$ The initial assessment was done within three and six months post stroke, and a follow-up assessment 14 months later. At baseline, patients were categorized based on severity into three groups: vascular dementia, vascular cognitive impairment no dementia (VCI-ND) and no cognitive impairment. Cognitive tests showed a mean decline of 0.83 points on MMSE between the two time points. Patients impaired at baseline assessment (vascular dementia + VCI-ND), showed a greater decline in visuoconstructive function and abstraction domains than patients with no cognitive impairment. In this study, higher white matter hyperintensity load was a significant predictor of cognitive decline. Education level emerged as a protective factor against cognitive decline following the TIA/stroke. Another study assessed cognitive function in 252 patients with TIA or non-disabling ischemic stroke at baseline (within six months of symptom onset) and again after one year. ${ }^{9}$ At baseline, after administering MMSE along with the vascular dementia battery, $56 \%$ of patients were 'cognitively intact', $40 \%$ were 'cognitively impaired but not demented' and $4 \%$ were 'demented'. Of the 252 patients, only 155 were reassessed at the one year follow-up. Of these patients, 120 remained in the same categories as at baseline. Nineteen patients (12\%) cognitively impaired but not demented at baseline, improved to the point they were considered cognitively intact at one year. Nine patients cognitively intact at baseline, deteriorated to cognitively impaired but not demented at the one year follow-up and seven patients who were cognitively impaired but not demented at baseline were demented at one year. Demographic variables that differentiated those who deteriorated from those who remained stable or improved included hypertension, age, years of education and MMSE score.

\section{Knowledge Gaps}

Most of these studies included patients with large and often disabling strokes. It is therefore unsurprising that cognition is affected in these patients, particularly as many have pre-existing deficits. What remains unknown is the extent that TIA affects cognition and what the temporal profile of any changes is. Accurate predictors of improvement/worsening in cognitive status after TIA/minor stroke are also unknown.

\section{Therapeutics and Management of Cognitive Decline}

Treatment and management of cognitive decline is critical to patient care and preventing prolonged disability following stroke. There is currently no standard treatment for VCI.

\section{Prevention of Vascular Dementia: Vascular Risk Factor Management}

\section{Hypertension}

Hypertension is an established risk factor for cardiovascular disease and stroke. A number of studies have identified a blood pressure threshold of $130 / 80 \mathrm{mmHg}$ above which strokes are more likely to occur. ${ }^{71,72}$ Hypertension has also been implicated in affecting cognitive function. A recent systematic review investigated the association of arterial hypertension with increased risk of vascular dementia. ${ }^{73}$ Results demonstrated that people with midlife hypertension have a doubled risk of developing vascular dementia comparing to those without hypertension.

There is some evidence suggesting treatment of hypertension decreases the risk of dementia. Published studies have found that lowering blood pressure in the middle aged or younger elderly population can be useful for the prevention of late life dementia. A few major randomized controlled trials have reported positive effects of antihypertensive treatment on cognitive function in patients with cerebrovascular disease. The Heart Outcomes Prevention Evaluation (HOPE) study was a randomized double blind study of 1013 high-risk patients with a history of stroke or TIA. ${ }^{74}$ The study showed that significantly fewer patients 
demonstrated cognitive impairment when treated with angiotensin-converting enzyme inhibitor (ACE-I) ramipril compared to placebo. Given the mild lowering of blood pressure however, it is hard to be certain that these cognitive benefits were a direct result of ramipril. In the Systolic Hypertension in Europe (Syst-Eur) trial, 2148 patients were randomized to active treatment with nitrendipine or placebo control. ${ }^{75}$ Results showed that the rate of incident dementia was reduced by $50 \%$. The Perindopril Protection Against Recurrent Stroke Study (PROGRESS) was a randomized, double blind, placebo controlled trial of 3015 patients with prior stroke or TIA. ${ }^{76}$ Patients were assigned to the active treatment group (with perindopril or indapamide) or the matched placebo group, with cognitive function assessed at baseline, 6-month and 12-month visits with MMSE. At the mean follow-up of 3.9 years, the actively treated group demonstrated a $12 \%$ reduced risk of dementia and a $19 \%$ reduced risk of cognitive decline, compared to matched placebo group.

\section{Dyslipidemia}

High cholesterol has also shown a consistent association with both increased risk of Alzheimer's disease and vascular dementia. In the Kaiser Permanente Northern California Medical Group study of 469 individuals between the ages of 40-45, serum total cholesterol levels were strongly associated with the increased risk of vascular dementia and Alzheimer's disease three decades later. ${ }^{77}$ This study echoed the results of previous trials including the Finnish Cohort of the Seven Countries Study $^{78}$ and the CAIDE study ${ }^{79}$ where high midlife cholesterol levels were associated with vascular dementia and Alzheimer's disease later in life.

As a result, various trials have investigated the use of statins and serum cholesterol reduction in the prevention of dementia and cognitive impairment. In a recent study, 3005 participants were recruited from the Baltimore Longitudinal Study of Aging after the age of 50 , and followed for a mean 25 years to investigate incidence of dementia and MCI. ${ }^{80}$ Participants with incident dementia had higher total cholesterol measured at the first visit and statin users had a two - three fold lower risk of developing dementia. Similarly, data from the Rotterdam study demonstrated that statin use was associated with a decreased risk of Alzheimer's disease compared to never using cholesterollowering drugs, in patients that were followed up to 15.3 years (mean 9.2). ${ }^{81}$ Based on a recent Cochrane review, the use of statins has not consistently demonstrated positive results in all randomized controlled trials. ${ }^{82}$

\section{Diabetes Mellitus}

Diabetes is a strong risk factor for cerebrovascular disease but epidemiological evidence has shown a relationship between cognitive impairment and Type II diabetes. Hypoglycemia and hyperglycemia have both been linked to impairments in cognitive function suggesting there may be an optimal neuroglycemic range within which cognitive functioning takes place. ${ }^{83,84}$ In a systematic review investigating the association between diabetes and incidence of major types of dementia, 14 longitudinal studies identified higher incidence of "any dementia" in individuals with diabetes, this highest risk being for Alzheimer's disease and vascular dementia. ${ }^{85}$
There has been no evidence to suggest that control of glucose levels reduces the risk of dementia or prevents cognitive impairment. A recent systematic review identified five randomized controlled trials assessing the effects of different treatments for Type II diabetes on cognitive function. ${ }^{86}$ One study compared ginseng with placebo 36 patients being treated by diet alone (no insulin or oral hypoglycemic agents prescribed) ${ }^{87}$ Cognitive function was tested after eight weeks using digit span and a timed diagram test. Ginseng treated patients had better scores on the diagram test and no differences in digit span compared to placebo, but scores at baseline were not reported, making this result somewhat difficult to interpret. In three of the identified studies, patients given different diabetic treatments were assessed using quality of life questionnaires as opposed to a validated quantitative measure of cognitive function. ${ }^{88,89}$ The final study compared the effect of intensive inpatient diabetic therapy with unchanged regular diabetic therapy on 20 patients already being treated by diet and oral antidiabetic drugs. ${ }^{90}$ Cognitive function was assessed on admission, at discharge and at six weeks. At six weeks mean cognitive scores of the intensive therapy group were significantly better than those of the regular therapy group. There is still, therefore, a lack of convincing evidence relating diabetes management to the prevention or improvement of cognitive impairment.

\section{Symptomatic Management of Cognitive Symptoms}

\section{Pharmacological}

\section{Cholinesterase Inhibitors}

Cholinesterase inhibitors are commonly used in temporarily treating or stabilizing symptoms of Alzheimer's disease. Evidence that disrupted cholinergic pathways may contribute to the pathophysiology of vascular dementia as well, have led to several clinical trials of cholinesterase inhibitors in the management of vascular dementia. Compared to other studies, controlled clinical trials with donepezil and galantamine in patients with vascular dementia have demonstrated improvement in cognition, behavior and activities of daily living ${ }^{91-98}$ (Table 3).

Donepzeil is a non-competitive, reversible antagonist of cholinesterase, licensed for the treatment of Alzheimer's disease in the United Kingdom and the United States. Two large-scale multi-center, randomized controlled trials (Study $307^{92}$ and Study $308^{93}$ ) were conducted in patients with probable or possible VCI according to the NINDS-AIREN criteria. Patients in both studies were randomized to 24 weeks of donepezil treatment $(5 \mathrm{mg} /$ day or $10 \mathrm{mg} /$ day $)$ or placebo with primary efficacy outcome measures being the ADAS-cog and the Clinician's Interview Based Impression of Change (CIBIC). In study 307, 603 patients were assessed at baseline, 6, 12, 18 and 24 weeks. $^{92}$ Both donepezil treatment groups demonstrated a significant improvement in cognition versus the placebo on the ADAS-cog at all time points. In study $308(n=616$ patients $)$, the donepezil treatment group showed the same statistically significant improvement in cognition by week 24 when measured with the ADAS-cog. ${ }^{93}$ A recent larger double-blind randomized controlled trial was conducted at 111 centers in 9 countries investigating 974 patients with probable or possible vascular dementia. ${ }^{94}$ Patients were randomized to receive donepezil $5 \mathrm{mg} /$ day or placebo for 24 weeks. Patients treated 
Table 3: Pharmacological evidence for treatment of vascular dementia

\begin{tabular}{|c|c|c|c|c|c|}
\hline Treatment & Study Reference & $\begin{array}{l}\text { Trial } \\
\text { Duration }\end{array}$ & Dosage & Participants & Measured Outcomes \\
\hline Donepezil & $\begin{array}{l}\text { Black et al. }{ }^{92} \\
\text { (Donepezil 307) }\end{array}$ & 24 wks & $\begin{array}{l}5 \mathrm{mg} \text { daily and } 10 \\
\text { mg daily }\end{array}$ & $\begin{array}{l}603 \text { patients with probable or possible } \\
\text { vascular dementia by NINDS-AIREN }\end{array}$ & $\begin{array}{l}\text { ADAS-cog and CIBIC } \\
\text { improvement in both } \\
\text { treatment group }\end{array}$ \\
\hline Donepezil & $\begin{array}{l}\text { Wilkinson et al. }{ }^{93} \\
\text { (Donepezil 308) }\end{array}$ & 24 wks & $\begin{array}{l}\text { 5mg daily and } 10 \\
\text { mg daily }\end{array}$ & $\begin{array}{l}616 \text { patients with probable or possible } \\
\text { vascular dementia by NINDS-AIREN }\end{array}$ & $\begin{array}{l}\text { ADAS-cog and CIBIC } \\
\text { improvement in both } \\
\text { treatment groups }\end{array}$ \\
\hline Donepezil & Roman et al. $^{94}$ & 24 wks & $5 \mathrm{mg}$ daily & $\begin{array}{l}974 \text { patients with probable or possible } \\
\text { vascular dementia by NINDS-AIREN }\end{array}$ & $\begin{array}{l}\text { VADAS-cog improvement } \\
\text { in treatment group }\end{array}$ \\
\hline Galantamine & Erkinjuntti et al. $^{95}$ & 24 wks & $24 \mathrm{mg}$ daily & $\begin{array}{l}592 \text { patients with NINCDS-ADRDA } \\
\text { Alzheimer's disease with } \\
\text { cerebrovascular disease or vascular } \\
\text { dementia by NINDS-AIREN }\end{array}$ & $\begin{array}{l}\text { ADAS-cog improvement in } \\
\text { treatment group }\end{array}$ \\
\hline Galantamine & Auchus et al. ${ }^{96}$ & 26 wks & $\begin{array}{l}\text { Escalated to } \\
8 \mathrm{mg} \text { or } 12 \mathrm{mg} \\
\text { twice daily }\end{array}$ & $\begin{array}{l}788 \text { patients with probable vascular } \\
\text { dementia by NINDS-AIREN }\end{array}$ & $\begin{array}{l}\text { ADAS-cog/11 improvement } \\
\text { in treatment group }\end{array}$ \\
\hline Memantine & $\begin{array}{l}\text { Orgogozo et al. }{ }^{97} \\
\text { (MMM300) }\end{array}$ & 28 wks & 20mg daily & $\begin{array}{l}321 \text { patients with probable vascular } \\
\text { dementia by NINDS-AIREN }\end{array}$ & $\begin{array}{l}\text { ADAS-cog improvement in } \\
\text { treatment group }\end{array}$ \\
\hline Memantine & $\begin{array}{l}\text { Wilcock et al. } \\
\text { (MMM500) }\end{array}$ & 28 wks & $20 \mathrm{mg}$ daily & $\begin{array}{l}579 \text { patients with probable vascular } \\
\text { dementia by NINDS-AIREN }\end{array}$ & $\begin{array}{l}\text { ADAS-cog improvement in } \\
\text { treatment group }\end{array}$ \\
\hline
\end{tabular}

NINDS-AIREN indicates National Institute of Neurological Disorders and Stroke and Association Internationale pour la Recherché et l'Enseignement en Neurosciences; ADAS-cog, Alzheimer's Disease Assessment Scale-Cognitive Subscale; CIBIC, Clinician Interview Based Impression of Change; VADAS-cog, Vascular Alzheimer's disease Assessment Scale-Cognitive Subscale; NINCDS-ADRDA, National Institute of Neurological and Communicative Diseases and Stroke/Alzheimer's Disease and Related Disorders Association.

with donepezil showed significant improvement from baseline to end point based on the Vascular Alzheimer's disease Assessment Scale-Cognitive Subscale (VADAS-cog), compared to the relative stability of the placebo group. It is therefore recommended by the American Heart Association/American Stroke Association (AHA/ASA) that Donepezil can be useful for cognitive enhancement in patients with vascular dementia. ${ }^{99}$

Galantamine is a specific, competitive and reversible acetylcholinesterase inhibitor that has been shown to improve cognition and behavior in patients with Alzheimer's type dementia. ${ }^{100,101}$ In one randomized, placebo controlled trial, 592 patients with probable vascular dementia or Alzheimer's disease with cerebrovascular disease were randomized to placebo or galantamine $24 \mathrm{mg}$ /day for six months following a four week placebo period. ${ }^{95}$ According to the ADAS-cog scores, treatment group patients significantly improved from baseline to the six month period compared to those assigned placebo, whereas placebo group deteriorated below baseline. Another randomized placebo controlled trial investigated galantamine in 788 patients with probable vascular dementia using slow dose escalation up to 26 weeks. ${ }^{96}$ After a four week placebo run, patients were randomized to receive increasing doses of placebo or galantamine, initiated at $4 \mathrm{mg}$ twice daily and escalated to a final dose of 8 or $12 \mathrm{mg}$ twice daily. Improvements in ADAS-cog scores in those treated with galantamine were significantly greater compared with placebo after 26 weeks. The AHA/ASA guidelines therefore suggest that galantamine can be beneficial to patients with mixed Alzheimer's disease or vascular dementia. $^{99}$

\section{Glutamate Receptor Antagonists}

Glutamate is the principal excitatory neurotransmitter that stimulates N-methyl-D-aspartate (NDMA) receptors in cortical neurons. There is some evidence that sustained elevation of glutamate may underlie the neuronal loss that is observed in dementia. ${ }^{102}$ Ischemia has been associated with the repeated stimulation of NMDA receptors; agents that block the stimulation of this receptor may play a protective role, preventing further neurodegeneration leading to cognitive decline. Memantine is a NMDA receptor antagonist, shown to have neuro-protective effects that help improve cognitive performance in vascular dementia patients. ${ }^{97,103}$ There have been several clinical studies demonstrating memantine's effects on improving cognitive performance in dementia patients ${ }^{97,98,104}$ (Table 3). In one multicenter, randomized controlled trial, 321 patients with mild to moderate vascular dementia were randomly allocated to receive placebo or memantine. ${ }^{97}$ After a two week placebo run-in period, patients received doses of $20 \mathrm{mg} /$ day for 28 weeks to follow. Mean ADAS-cog scores showed that patients in the memantine group improved from baseline while the placebo group deteriorated in function. In a larger randomized controlled trial, 579 patients with probable vascular dementia were randomized to placebo or treatment with $20-\mathrm{mg} / \mathrm{d}$ memantine for 28 weeks. ${ }^{98}$ Memantine resulted in improvement in ADAS-cog scores, not seen in placebo treated patients. According to AHA/ASA, the benefits of memantine are not well established in vascular dementia. ${ }^{99}$ 


\section{Non-Pharamcological}

\section{Physical Activity}

Physical exercise has been associated with several beneficial effects including the reduced risk of Alzheimer's disease and cognitive decline. Many longitudinal studies in the health elderly have consistently found that regular physical activity was associated with better cognitive function and less cognitive decline later in life. A meta-analysis including 16 prospective studies of non-demented patients suggested that physical activity reduced the risk of dementia and Alzheimer's disease by $28 \%$ and $45 \%$ respectively. ${ }^{105}$

Studies targeting patients with Alzheimer's disease, vascular dementia and cognitive impairment have reported similar findings. A recently conducted systematic review included a total of 24 longitudinal studies of 1378 patients with vascular dementia. ${ }^{106}$ The meta-analysis technique was used to demonstrate a significant reduced risk for vascular dementia in people who were naturally more physically active compared to those who were not. A four month randomized controlled trial conducted in 40 patients diagnosed with Alzheimer's disease assessed the effectiveness of a community based home exercise program on improving cognitive and physical function. ${ }^{107}$ Patients were randomly assigned to usual treatment plus exercise or usual treatment alone groups. When assessed at baseline and the four month follow-up, patients who exercised had improved cognition compared to controls when assessed with MMSE. One meta-analysis reviewed 30 randomized controlled trials evaluating exercise in patients with cognitive impairments. ${ }^{108}$ Exercise was associated with statistically significant improvements in cognitive function as well as physical fitness.

\section{Education}

Higher levels of education have been associated with a reduced risk dementia and cognitive impairment during aging. It has yet to be determined if education protects from development of neurodegenerative brain pathology or if it increases the brain's resilience against dementia related pathology. The cognitive reserve hypothesis suggests that individuals exposed to an enriched environment through higher education will maintain higher cognitive function in later years by functionally compensating for any neurological load. ${ }^{109}$

Studies have examined the relationship between education levels and cognitive changes in both normal and demented adults. A recent systematic review aimed at investigating the cognitive reserve hypothesis in 133 quantitative studies including both healthy and Alzheimer's disease patients. ${ }^{110} \mathrm{~A}$ meta-analysis of this data showed that those with lower education levels had a higher risk for dementia. A longitudinal study of 630 cognitively healthy individuals aged 50 to 80 assessed educational level and mental demands at work as related to cognitive decline. ${ }^{111}$ At the three year follow-up, persons with low education (primary education and lower vocational secondary education) and lower mental workload showed accelerated cognitive decline in speed (Stroop Test) memory (Verbal Learning Test) and general cognitive status (MMSE).

There is current evidence that lifelong bilingualism is also a factor that protects against cognitive decline and the onset of dementia. ${ }^{112}$ In a recent study of 211 patients diagnosed with probable Alzheimer's disease, age, education and language history were recorded, classifying 102 patients as bilingual and 109 patients as monolingual. ${ }^{113}$ Results demonstrated that compared to monolinguals, bilingual patients had been diagnosed 4.3 years later and had reported the onset of symptoms 5.1 years later. A study investigating possible neural correlates of this effect tested the hypothesis that bilingualism is associated with maintenance of white matter integrity in older individuals. ${ }^{114}$ Results from diffusion tensor imaging showed stronger structural and functional connectivity in bilinguals compared to monolinguals.

Participation in cognitively stimulating activities has been hypothesized to reduce the risk of dementia cognitive decline, although evidence of this association is scarce. A longitudinal cohort study tested this hypothesis in 801 non-demented individuals evaluated at baseline and a mean follow-up of 4.5 years. ${ }^{115}$ Results showed that an individual reporting frequent cognitive activity at baseline had a $47 \%$ reduced chance of developing Alzheimer's disease. Another interesting study of 488 cognitively intact individuals assessed the effect of selfreported cognitive activities on the onset of cognitive decline. ${ }^{116}$ Findings showed that every additional self-reported day of cognitive activity at baseline, delayed the onset of accelerated memory decline by 0.18 years. These findings provide hope that engaging in cognitively stimulating activities may reduce the risk of dementia.

\section{Smoking}

Smoking has been associated with both cognitive decline and a significantly increased risk of vascular dementia and Alzheimer's disease. A meta-analysis conducted in 2007 identified 19 studies with at least 12 months of follow-up showing current smokers had an increased risk of dementia and cognitive decline ranging from $40-80 \%$ compared with people who have never smoked. ${ }^{117}$ Recently, a population based cohort study of 21,123 patients surveyed between 1978 and 1985 demonstrated that heavy smoking in midlife was associated with a greater than $100 \%$ increase in risk of dementia, Alzheimer's disease and vascular dementia more than 20 years later. ${ }^{118}$

Evidence that smoking cessation prevents cognitive impairment of onset of dementia is limited. The Honolulu-Asia Aging Study was one of the first to investigate smoking cessation and cognitive function. ${ }^{119}$ This study found that the odds of cognitive impairment was 36\% higher among continuous smokers than never smokers and significantly declined in long term quitters. A recent smoking cessation trial recruited 229 older smokers and 98 never smokers to assess how cessation in chronic smokers would affect rate of change in ADAS-cog scores measured over 24 months. ${ }^{120}$ Results demonstrated that chronic smokers who continued to smoke or stopped smoking for less than 18 months experienced greater cognitive decline and greater deterioration of memory scores over two years when compared with never smokers.

\section{Conclusion}

Cognitive changes are common in cerebrovascular patients. Although there is good evidence that patients with disabling stroke also have cognitive symptoms, there are less data related to TIA patients. Arguably, these are the more relevant patients to study, as they make functional recoveries, returning to live and 
work in the community. Assessment of cognition in acute stroke patients is challenging, due to the presence of other neurological deficits. This has led to under-recognition of the seriousness of cognitive changes in acute cerebrovascular disease patients, particularly those with minor or even apparently transient symptoms. Reliable predictors of cognitive impairment have not been identified, although imaging correlates may hold some promise. The temporal pattern of cognitive impairment after TIA has not yet been adequately characterized. Given the implications for patient rehabilitation, return to work, and activities of daily living, we suggest that this is a research priority.

\section{ACKNOWLEDGEMENTS}

KSB holds a Canada Research Chair in Cerebrovascular Disease, an Alberta Innovates Health Solutions New Investigator Award and the Heart and Stroke Foundation Professorship in Stroke Medicine at the University of Alberta.

\section{REFERENCES}

1. Donnan GA, Fisher M, Macleod M, Davis SM. Stroke. Lancet. 2008;371:1612-23.

2. Roger VL, Go AS, Lloyd-Jones DM, et al. Heart disease and stroke statistics--2011 update: a report from the American Heart Association. Circulation. 2011;123:e18-e209.

3. The World Health Organization MONICA Project (monitoring trends and determinants in cardiovascular disease): a major international collaboration. WHO MONICA Project Principal Investigators. J Clin Epidemiol. 1988;41:105-14.

4. Rothwell PM, Warlow CP. Timing of TIAs preceding stroke: time window for prevention is very short. Neurology. 2005;64: 817-20.

5. Desmond DW, Moroney JT, Sano M, Stern Y. Incidence of dementia after ischemic stroke: results of a longitudinal study. Stroke. 2002;33:2254-60.

6. Tatemichi TK, Desmond DW, Paik M, et al. Clinical determinants of dementia related to stroke. Ann Neurol. 1993;33:568-75.

7. Pendlebury ST, Wadling S, Silver LE, Mehta Z, Rothwell PM. Transient cognitive impairment in TIA and minor stroke. Stroke. 2011;42:3116-21.

8. Sachdev PS, Brodaty H, Valenzuela MJ, Lorentz LM, Koschera A. Progression of cognitive impairment in stroke patients. Neurology. 2004;63:1618-23

9. Tham W, Auchus AP, Thong M, et al. Progression of cognitive impairment after stroke: one year results from a longitudinal study of Singaporean stroke patients. J Neurol Sci. 2002;203204:49-52.

10. Ovbiagele B, Kidwell CS, Saver JL. Epidemiological impact in the United States of a tissue-based definition of transient ischemic attack. Stroke. 2003;34:919-24.

11. Fazekas F, Fazekas G, Schmidt R, Kapeller P, Offenbacher H. Magnetic resonance imaging correlates of transient cerebral ischemic attacks. Stroke. 1996;27:607-11.

12. Kidwell CS, Warach S. Acute ischemic cerebrovascular syndrome: diagnostic criteria. Stroke. 2003;34:2995-8.

13. Ay H, Oliveira-Filho J, Buonanno FS, et al. 'Footprints' of transient ischemic attacks: a diffusion-weighted MRI study. Cerebrovasc Dis. 2002;14:177-86.

14. Perrone P, Candelise L, Scotti G, De Grandi C, Scialfa G. CT evaluation in patients with transient ischemic attack. Correlation between clinical and angiographic findings. Eur Neurol. 1979; $18: 217-21$

15. Calandre L, Gomara S, Bermejo F, Millan JM, del Pozo G. ClinicalCT correlations in TIA, RIND, and strokes with minimum residuum. Stroke. 1984;15:663-6.

16. Awad I, Modic M, Little JR, Furlan AJ, Weinstein M. Focal parenchymal lesions in transient ischemic attacks: correlation of computed tomography and magnetic resonance imaging. Stroke. 1986;17:399-403.

17. Davalos A, Matias-Guiu J, Torrent O, Vilaseca J, Codina A. Computed tomography in reversible ischaemic attacks: clinical and prognostic correlations in a prospective study. J Neurol. 1988;235:155-8.

18. Murros KE, Evans GW, Toole JF, Howard G, Rose LA. Cerebral infarction in patients with transient ischemic attacks. J Neurol. 1989;236:182-4.

19. Dennis M, Bamford J, Sandercock P, Molyneux A, Warlow C. Computed tomography in patients with transient ischaemic attacks: when is a transient ischaemic attack not a transient ischaemic attack but a stroke? J Neurol. 1990;237:257-61.

20. Evans GW, Howard G, Murros KE, Rose LA, Toole JF. Cerebral infarction verified by cranial computed tomography and prognosis for survival following transient ischemic attack. Stroke. 1991;22:431-6.

21. Eliasziw M, Streifler JY, Spence JD, Fox AJ, Hachinski VC, Barnett HJ. Prognosis for patients following a transient ischemic attack with and without a cerebral infarction on brain CT. North American Symptomatic Carotid Endarterectomy Trial (NASCET) Group. Neurology. 1995;45:428-31.

22. Douglas VC, Johnston CM, Elkins J, Sidney S, Gress DR, Johnston SC. Head computed tomography findings predict short-term stroke risk after transient ischemic attack. Stroke. 2003;34: 2894-8.

23. Al-Khaled M, Matthis C, Munte TF, Eggers J. Use of cranial CT to identify a new infarct in patients with a transient ischemic attack. Brain Behav. 2012;2:377-81.

24. Waxman SG, Toole JF. Temporal profile resembling TIA in the setting of cerebral infarction. Stroke. 1983;14:433-7.

25. Nentwich LM, Veloz W. Neuroimaging in acute stroke. Emerg Med Clin North Am. 2012;30:659-80.

26. Forster A, Gass A, Kern R, et al. Brain imaging in patients with transient ischemic attack: a comparison of computed tomography and magnetic resonance imaging. Eur Neurol. 2012; 67:136-41.

27. Kidwell CS, Alger JR, Di Salle F, et al. Diffusion MRI in patients with transient ischemic attacks. Stroke. 1999;30:1174-80.

28. Engelter ST, Provenzale JM, Petrella JR, Alberts MJ. Diffusion MR imaging and transient ischemic attacks. Stroke. 1999;30:2762-3.

29. Takayama H, Mihara B, Kobayashi M, Hozumi A, Sadanaga H, Gomi S. [Usefulness of diffusion-weighted MRI in the diagnosis of transient ischemic attacks]. No To Shinkei. 2000;52:919-23.

30. Kamal AK, Segal AZ, Ulug AM. Quantitative diffusion-weighted MR imaging in transient ischemic attacks. AJNR Am J Neuroradiol. 2002;23:1533-8.

31. Marx JJ, Mika-Gruettner A, Thoemke F, et al. Diffusion weighted magnetic resonance imaging in the diagnosis of reversible ischaemic deficits of the brainstem. J Neurol Neurosurg Psychiatry. 2002;72:572-5.

32. Kastrup A, Schulz JB, Mader I, Dichgans J, Kuker W. Diffusionweighted MRI in patients with symptomatic internal carotid artery disease. J Neurol. 2002;249:1168-74.

33. Rovira A, Rovira-Gols A, Pedraza S, Grive E, Molina C, AlvarezSabin J. Diffusion-weighted MR imaging in the acute phase of transient ischemic attacks. AJNR Am J Neuroradiol. 2002;23: 77-83.

34. Crisostomo RA, Garcia MM, Tong DC. Detection of diffusionweighted MRI abnormalities in patients with transient ischemic attack: correlation with clinical characteristics. Stroke. 2003;34: 932-7.

35. Nagura J, Suzuki K, Johnston SC, et al. Diffusion-weighted MRI in evaluation of transient ischemic attack. J Stroke Cerebrovasc Dis. 2003; 12:137-42.

36. Nakamura T, Uchiyama S, Shibagaki Y, Iwata M. [Abnormalities on diffusion-weighted magnetic resonance imaging in patients with transient ischemic attack]. Rinsho Shinkeigaku. 2003;43: 122-5.

37. Restrepo L, Jacobs MA, Barker PB, Wityk RJ. Assessment of transient ischemic attack with diffusion- and perfusion-weighted imaging. AJNR Am J Neuroradiol. 2004;25:1645-52. 
38. Purroy F, Montaner J, Rovira A, Delgado P, Quintana M, AlvarezSabin J. Higher risk of further vascular events among transient ischemic attack patients with diffusion-weighted imaging acute ischemic lesions. Stroke. 2004;35:2313-19.

39. Winbeck K, Bruckmaier K, Etgen T, von Einsiedel HG, Rottinger M, Sander D. Transient ischemic attack and stroke can be differentiated by analyzing early diffusion-weighted imaging signal intensity changes. Stroke. 2004;35:1095-9.

40. Schulz UG, Briley D, Meagher T, Molyneux A, Rothwell PM. Diffusion-weighted MRI in 300 patients presenting late with subacute transient ischemic attack or minor stroke. Stroke. 2004; 35:2459-65.

41. Inatomi Y, Kimura K, Yonehara T, Fujioka S, Uchino M. DWI abnormalities and clinical characteristics in TIA patients. Neurology. 2004;62:376-80.

42. Ay H, Koroshetz WJ, Benner T, et al. Transient ischemic attack with infarction: a unique syndrome? Ann Neurol. 2005;57:679-86.

43. Coutts SB, Simon JE, Eliasziw M, et al. Triaging transient ischemic attack and minor stroke patients using acute magnetic resonance imaging. Ann Neurol. 2005;57:848-54.

44. Oppenheim C, Lamy C, Touze E, et al. Do transient ischemic attacks with diffusion-weighted imaging abnormalities correspond to brain infarctions? AJNR Am J Neuroradiol. 2006; 27:1782-7.

45. Lamy C, Oppenheim C, Calvet D, et al. Diffusion-weighted MR imaging in transient ischaemic attacks. Eur Radiol. 2006;16: 1090-5.

46. Prabhakaran S. Reversible brain ischemia: lessons from transient ischemic attack. Curr Opin Neurol. 2007;20:65-70.

47. Redgrave JN, Schulz UG, Briley D, Meagher T, Rothwell PM. Presence of acute ischaemic lesions on diffusion-weighted imaging is associated with clinical predictors of early risk of stroke after transient ischaemic attack. Cerebrovasc Dis. 2007; 24:86-90.

48. Calvet D, Touze E, Oppenheim C, Turc G, Meder JF, Mas JL. DWI lesions and TIA etiology improve the prediction of stroke after TIA. Stroke. 2009;40:187-92.

49. Mlynash M, Olivot JM, Tong DC, et al. Yield of combined perfusion and diffusion MR imaging in hemispheric TIA. Neurology. 2009;72:1127-33

50. Adeoye O, Heitsch L, Moomaw CJ, et al. How much would performing diffusion-weighted imaging for all transient ischemic attacks increase MRI utilization? Stroke. 2010;41: 2218-22.

51. Al-Khaled M, Matthis C, Munte TF, Eggers J. The incidence and clinical predictors of acute infarction in patients with transient ischemic attack using MRI including DWI. Neuroradiology. 2013;55:157-63.

52. Miyagi T, Uehara T, Kimura K, et al. Examination timing and lesion patterns in diffusion-weighted magnetic resonance imaging of patients with classically defined transient ischemic attack. J Stroke Cerebrovasc Dis. 2013;22:e310-16.

53. Sachdev PS, Brodaty H, Valenzuela MJ, et al. The neuropsychological profile of vascular cognitive impairment in stroke and TIA patients. Neurology. 2004;62:912-19.

54. Folstein MF, Robins LN, Helzer JE. The Mini-Mental State Examination. Arch Gen Psychiatry. 1983;40:812.

55. Nasreddine ZS, Phillips NA, Bedirian V, et al. The Montreal Cognitive Assessment, MoCA: a brief screening tool for mild cognitive impairment. J Am Geriatr Soc. 2005;53:695-9.

56. Pendlebury ST, Cuthbertson FC, Welch SJ, Mehta Z, Rothwell PM. Underestimation of cognitive impairment by Mini-Mental State Examination versus the Montreal Cognitive Assessment in patients with transient ischemic attack and stroke: a populationbased study. Stroke. 2010;41:1290-3.

57. Lenzi GL, Altieri M, Maestrini I. Post-stroke depression. Rev Neurol (Paris). 2008; 164:837-40

58. Kimura M, Robinson RG, Kosier JT. Treatment of cognitive impairment after poststroke depression: a double-blind treatment trial. Stroke. 2000;31:1482-6.

59. Kouwenhoven SE, Kirkevold M, Engedal K, Kim HS. Depression in acute stroke: prevalence, dominant symptoms and associated factors. A systematic literature review. Disabil Rehabil. 2011; 33:539-56.

60. Dong Y, Sharma VK, Chan BP, et al. The Montreal Cognitive Assessment (MoCA) is superior to the Mini-Mental State Examination (MMSE) for the detection of vascular cognitive impairment after acute stroke. J Neurol Sci. 2010;299:15-18.

61. Toglia J, Fitzgerald KA, O'Dell MW, Mastrogiovanni AR, Lin CD. The Mini-Mental State Examination and Montreal Cognitive Assessment in persons with mild subacute stroke: relationship to functional outcome. Arch Phys Med Rehabil. 2011;92:792-8.

62. Godefroy O, Fickl A, Roussel M, et al. Is the Montreal Cognitive Assessment superior to the Mini-Mental State Examination to detect poststroke cognitive impairment? A study with neuropsychological evaluation. Stroke. 2011;42:1712-16.

63. Pendlebury ST, Mariz J, Bull L, Mehta Z, Rothwell PM. MoCA, ACE-R, and MMSE versus the National Institute of Neurological Disorders and Stroke-Canadian Stroke Network Vascular Cognitive Impairment Harmonization Standards Neuropsychological Battery after TIA and stroke. Stroke. 2012; 43:464-9.

64. Pendlebury ST, Welch SJ, Cuthbertson FC, Mariz J, Mehta Z, Rothwell PM. Telephone assessment of cognition after transient ischemic attack and stroke: modified telephone interview of cognitive status and telephone Montreal Cognitive Assessment versus face-to-face Montreal Cognitive Assessment and neuropsychological battery. Stroke. 2013;44:227-9.

65. Shopin L, Shenhar-Tsarfaty S, Ben Assayag E, et al. Cognitive Assessment in Proximity to Acute Ischemic Stroke/Transient Ischemic Attack: Comparison of the Montreal Cognitive Assessment Test and MindStreams Computerized Cognitive Assessment Battery. Dement Geriatr Cogn Disord. 2013;36: 36-42.

66. Roman GC, Tatemichi TK, Erkinjuntti T, et al. Vascular dementia: diagnostic criteria for research studies. Report of the NINDSAIREN International Workshop. Neurology. 1993;43:250-60.

67. Rosen WG, Mohs RC, Davis KL. A new rating scale for Alzheimer's disease. Am J Psychiatry. 1984;141:1356-64.

68. Connor DJ, Sabbagh MN. Administration and scoring variance on the ADAS-Cog. J Alzheimers Dis. 2008;15:461-4.

69. MacKenzie G, Gould L, Ireland S, LeBlanc K, Sahlas D. Detecting cognitive impairment in clients with mild stroke or transient ischemic attack attending a stroke prevention clinic. Can $\mathrm{J}$ Neurosci Nurs. 2011;33:47-50.

70. Wang L, Jia J, Wu L. The relationship between cognitive impairment and cerebral blood flow changes after transient ischaemic attack. Neurol Res. 2013;35:580-5.

71. Benavente OR, Hart RG, McClure LA, Szychowski JM, Coffey CS, Pearce LA. Effects of clopidogrel added to aspirin in patients with recent lacunar stroke. N Engl J Med. 2012;367:817-25.

72. Chobanian AV, Bakris GL, Black HR, et al. The Seventh Report of the Joint National Committee on Prevention, Detection, Evaluation, and Treatment of High Blood Pressure: the JNC 7 report. JAMA. 2003;289:2560-72.

73. Sharp SI, Aarsland D, Day S, Sonnesyn H, Ballard C. Hypertension is a potential risk factor for vascular dementia: systematic review. Int J Geriatr Psychiatry. 2011;26:661-9.

74. Bosch J, Yusuf S, Pogue J, et al. Use of ramipril in preventing stroke: double blind randomised trial. BMJ. 2002;324:699-702.

75. Forette F, Seux ML, Staessen JA, et al. Prevention of dementia in randomised double-blind placebo-controlled Systolic Hypertension in Europe (Syst-Eur) trial. Lancet. 1998;352: 1347-51.

76. Tzourio C, Anderson C, Chapman N, et al. Effects of blood pressure lowering with perindopril and indapamide therapy on dementia and cognitive decline in patients with cerebrovascular disease. Arch Intern Med. 2003;163:1069-75.

77. Solomon A, Kivipelto M, Wolozin B, Zhou J, Whitmer RA. Midlife serum cholesterol and increased risk of Alzheimer's and vascular dementia three decades later. Dement Geriatr Cogn Disord. 2009;28:75-80.

78. Menotti A, Blackburn $\mathrm{H}$, Kromhout $\mathrm{D}$, et al. Changes in population cholesterol levels and coronary heart disease deaths in seven countries. Eur Heart J. 1997;18:566-71. 
79. Kivipelto M, Helkala EL, Laakso MP, et al. Apolipoprotein E epsilon4 allele, elevated midlife total cholesterol level, and high midlife systolic blood pressure are independent risk factors for late-life Alzheimer disease. Ann Intern Med. 2002;137:149-55.

80. Beydoun MA, Beason-Held LL, Kitner-Triolo MH, et al. Statins and serum cholesterol's associations with incident dementia and mild cognitive impairment. J Epidemiol Community Health. 2011;65:949-57

81. Haag MD, Hofman A, Koudstaal PJ, Stricker BH, Breteler MM. Statins are associated with a reduced risk of Alzheimer disease regardless of lipophilicity. The Rotterdam Study. J Neurol Neurosurg Psychiatry. 2009;80:13-17.

82. McGuinness B, O'Hare J, Craig D, Bullock R, Malouf R, Passmore P. Cochrane review on 'Statins for the treatment of dementia'. Int J Geriatr Psychiatry. 2013;28:119-26.

83. Cox DJ, Kovatchev BP, Gonder-Frederick LA, et al. Relationships between hyperglycemia and cognitive performance among adults with type 1 and type 2 diabetes. Diabetes Care. 2005;28: 71-7.

84. McNay EC. The impact of recurrent hypoglycemia on cognitive function in aging. Neurobiol Aging. 2005;26 Suppl 1:76-9.

85. Biessels GJ, Staekenborg S, Brunner E, Brayne C, Scheltens P. Risk of dementia in diabetes mellitus: a systematic review. Lancet Neurol. 2006;5:64-74

86. Areosa SA, Grimley EV. Effect of the treatment of Type II diabetes mellitus on the development of cognitive impairment and dementia. Cochrane Database Syst Rev. 2002:CD003804.

87. Sotaniemi EA, Haapakoski E, Rautio A. Ginseng therapy in noninsulin-dependent diabetic patients. Diabetes Care. 1995;18: 1373-5.

88. Testa MA, Simonson DC. Health economic benefits and quality of life during improved glycemic control in patients with type 2 diabetes mellitus: a randomized, controlled, double-blind trial. JAMA. 1998;280:1490-6.

89. Quality of life in type 2 diabetic patients is affected by complications but not by intensive policies to improve blood glucose or blood pressure control (UKPDS 37). U.K. Prospective Diabetes Study Group. Diabetes Care. 1999;22: 1125-36.

90. Naor M, Steingruber HJ, Westhoff K, Schottenfeld-Naor Y, Gries AF. Cognitive function in elderly non-insulin-dependent diabetic patients before and after inpatient treatment for metabolic control. J Diabetes Complications. 1997;11:40-6.

91. Erkinjuntti T, Roman G, Gauthier S, Feldman H, Rockwood K. Emerging therapies for vascular dementia and vascular cognitive impairment. Stroke. 2004;35:1010-17.

92. Black S, Roman GC, Geldmacher DS, et al. Efficacy and tolerability of donepezil in vascular dementia: positive results of a 24-week, multicenter, international, randomized, placebocontrolled clinical trial. Stroke. 2003;34:2323-30.

93. Wilkinson D, Doody R, Helme R, et al. Donepezil in vascular dementia: a randomized, placebo-controlled study. Neurology. 2003;61:479-86.

94. Roman GC, Salloway S, Black SE, et al. Randomized, placebocontrolled, clinical trial of donepezil in vascular dementia: differential effects by hippocampal size. Stroke. 2010;41: 1213-21.

95. Erkinjuntti T, Kurz A, Gauthier S, Bullock R, Lilienfeld S, Damaraju CV. Efficacy of galantamine in probable vascular dementia and Alzheimer's disease combined with cerebrovascular disease: a randomised trial. Lancet. 2002;359: 1283-90.

96. Auchus AP, Brashear HR, Salloway S, Korczyn AD, De Deyn PP, Gassmann-Mayer C. Galantamine treatment of vascular dementia: a randomized trial. Neurology. 2007;69:448-58.

97. Orgogozo JM, Rigaud AS, Stoffler A, Mobius HJ, Forette F. Efficacy and safety of memantine in patients with mild to moderate vascular dementia: a randomized, placebo-controlled trial (MMM 300). Stroke. 2002;33:1834-9.

98. Wilcock G, Mobius HJ, Stoffler A. A double-blind, placebocontrolled multicentre study of memantine in mild to moderate vascular dementia (MMM500). Int Clin Psychopharmacol. 2002; 17:297-305.
99. Gorelick PB, Scuteri A, Black SE, et al. Vascular contributions to cognitive impairment and dementia: a statement for healthcare professionals from the American Heart Association/American Stroke Association. Stroke. 2011;42:2672-713.

100. Wilcock GK, Lilienfeld S, Gaens E. Efficacy and safety of galantamine in patients with mild to moderate Alzheimer's disease: multicentre randomised controlled trial. Galantamine International-1 Study Group. BMJ. 2000;321:1445-9.

101. Raskind MA, Peskind ER, Wessel T, Yuan W. Galantamine in AD: a 6-month randomized, placebo-controlled trial with a 6-month extension. The Galantamine USA-1 Study Group. Neurology. 2000;54:2261-8

102. Kornhuber J, Wiltfang J. The role of glutamate in dementia. J Neural Transm Suppl. 1998;53:277-87.

103. Thomas SJ, Grossberg GT. Memantine: a review of studies into its safety and efficacy in treating Alzheimer's disease and other dementias. Clin Interv Aging. 2009;4:367-77.

104. Molinuevo JL, Llado A, Rami L. Memantine: targeting glutamate excitotoxicity in Alzheimer's disease and other dementias. Am J Alzheimers Dis Other Demen. 2005;20:77-85.

105. Hamer M, Chida Y. Physical activity and risk of neurodegenerative disease: a systematic review of prospective evidence. Psychol Med. 2009;39:3-11.

106. Aarsland D, Sardahaee FS, Anderssen S, Ballard C. Is physical activity a potential preventive factor for vascular dementia? A systematic review. Aging Ment Health. 2010;14:386-95.

107. Vreugdenhil A, Cannell J, Davies A, Razay G. A community-based exercise programme to improve functional ability in people with Alzheimer's disease: a randomized controlled trial. Scand J Caring Sci. 2012;26:12-19.

108. Littbrand H, Stenvall M, Rosendahl E. Applicability and effects of physical exercise on physical and cognitive functions and activities of daily living among people with dementia: a systematic review. Am J Phys Med Rehabil. 2011;90:495-518.

109. Tucker-Drob EM, Johnson KE, Jones RN. The cognitive reserve hypothesis: a longitudinal examination of age-associated declines in reasoning and processing speed. Dev Psychol. 2009; 45:431-46.

110. Meng X, D'Arcy C. Education and dementia in the context of the cognitive reserve hypothesis: a systematic review with metaanalyses and qualitative analyses. PLoS One. 2012;7:e38268.

111. Bosma H, van Boxtel MP, Ponds RW, Houx PJ, Burdorf A, Jolles J. Mental work demands protect against cognitive impairment: MAAS prospective cohort study. Exp Aging Res. 2003;29: 33-45.

112. Bialystok E, Craik FI, Luk G. Bilingualism: consequences for mind and brain. Trends Cogn Sci. 2012;16:240-50.

113. Craik FI, Bialystok E, Freedman M. Delaying the onset of Alzheimer disease: bilingualism as a form of cognitive reserve. Neurology. 2010;75:1726-9.

114. Luk G, Bialystok E, Craik FI, Grady CL. Lifelong bilingualism maintains white matter integrity in older adults. J Neurosci. 2011;31:16808-13

115. Wilson RS, Mendes De Leon CF, Barnes LL, et al. Participation in cognitively stimulating activities and risk of incident Alzheimer disease. JAMA. 2002;287:742-8.

116. Hall CB, Lipton RB, Sliwinski M, Katz MJ, Derby CA, Verghese J. Cognitive activities delay onset of memory decline in persons who develop dementia. Neurology. 2009;73:356-61.

117. Anstey KJ, von Sanden C, Salim A, O'Kearney R. Smoking as a risk factor for dementia and cognitive decline: a meta-analysis of prospective studies. Am J Epidemiol. 2007;166:367-78.

118. Rusanen M, Kivipelto M, Quesenberry CP, Jr., Zhou J, Whitmer RA. Heavy smoking in midlife and long-term risk of Alzheimer disease and vascular dementia. Arch Intern Med. 2011;171: 333-9.

119. Tyas SL, White LR, Petrovitch H, et al. Mid-life smoking and latelife dementia: the Honolulu-Asia Aging Study. Neurobiol Aging. 2003;24:589-96.

120. Almeida OP, Garrido GJ, Alfonso H, et al. 24-month effect of smoking cessation on cognitive function and brain structure in later life. Neuroimage. 2011;55:1480-9. 